\title{
Magnetic and Electrical Properties of $\mathrm{Mn}_{x} \mathrm{Cu}_{1-x} \mathrm{Fe}_{2} \mathrm{O}_{4}$ Ferrite
}

\author{
Valesca Donizeti de Oliveira ${ }^{a}$, Rero Marques Rubinger ${ }^{a}$, Manoel Ribeiro da Silva ${ }^{a}$, Adhimar Flávio \\ Oliveira $^{a}$, Geovani Rodrigues ${ }^{a}$, Vander Alkmin dos Santos Ribeiro ${ }^{a}$ \\ ${ }^{a}$ Federal University of Itajubá - UNIFEI, Av. BPS, 1303, Bairro Pinheirinho, Caixa Postal 50, CEP: \\ 37500-093, Itajubá, MG, Brazil
}

Received: August 31, 2015; Revised: December 21, 2015; Accepted: May 10, 2016

In the present work, mixed manganese-copper ferrite of composition $\mathrm{Mn}_{\mathrm{x}} \mathrm{Cu}_{1-\mathrm{x}} \mathrm{Fe}_{2} \mathrm{O}_{4}$ (within $\mathrm{x}=0.40$, $0.42,0.44,0.46,0.48$ and 0.50 ) have been investigated for their electric and magnetic properties such as dc resistivity, Curie temperature, saturation magnetization. $\mathrm{Mn}_{\mathrm{x}} \mathrm{Cu}_{1-\mathrm{x}} \mathrm{Fe}_{2} \mathrm{O}_{4}$ ferrite samples were prepared by uniaxial pressing from the oxide mixture, synthesized at $1000^{\circ} \mathrm{C}$ during 45 hours and finally heated to $1200^{\circ} \mathrm{C}$ by $5 \mathrm{~h}$, at room atmosphere. The X-ray diffractograms show that the samples with different compositions were formed by compact structure spinel with cubic cell. The saturated magnetization of the $\mathrm{Mn}_{\mathrm{x}} \mathrm{Cu}_{1-\mathrm{x}} \mathrm{Fe}_{2} \mathrm{O}_{4}$ ferrites increased with $\mathrm{x}$ up to 0.46 , which presented the smallest coercitive field. All samples showed hysteresis characteristic of soft magnetic materials. This electrical behavior is compatible with an insulator. The results were analyzed in the framework of grain/barrier model.

Keywords: Ferrites, Spinel Structure, Magnetic Properties, Mn-Cu ferrites

\section{Introduction}

Mixed manganese/copper ferrites having high Curie temperatures and magnetization depending on the composition form an important class of magnetic materials used in many technological application ${ }^{1}$.

The magnetic particles with smaller size become single domain in contrast with the usual multi domain structure for bulk magnetic material exhibiting superparamagnetization. Magnetic particles exhibiting superparamagnetic behavior display higher saturation magnetization and low coercivity having potential applications e.g., as magnetic resonance imaging contrast agents, in ferrofluids based technology, information storage device, gas sensors ${ }^{2}$. For instance, a recent application of mixed ferrite $\mathrm{Mn}-\mathrm{Cu}$ is a methane gas sensor for the oil industry ${ }^{3}$. The magnetic properties and gassensing efficiency of the material depends on its microstructural properties, which are related to its method of preparation.

The synthesis of spinel manganese ferrite has been investigated extensively in recent years due to their structural, thermal, physical, chemical and particularly due to their magnetic properties ${ }^{4,5}$. Those characteristics are in close connection with the magnetic structure, which is dependent on the magnetic cations, their distribution and concentration ${ }^{6}$. The $\mathrm{MnFe}_{2} \mathrm{O}_{4}$ is an important member of spinel structured ferrite class due to their excellent properties such as high saturation magnetization, high initial permeability, high resistivity and low losses ${ }^{5}$.

This system has a cubic spinel crystal structure with the unit cell consisting of eight units of the form $\left[\mathrm{M}_{\delta} \mathrm{Fe}_{1-\delta}\right]$ ${ }^{\mathrm{A}}\left[\mathrm{M}_{1-\delta} \mathrm{Fe}_{1+\delta}\right]^{\mathrm{B}} \mathrm{O}_{4}$, where $\delta$ is a composition and acts as the inversion parameter with $\delta=0$ (1) standing for the inverse (normal) case. The 32 oxygen anions per unit cell form a

* e-mail: valescaoliveira@unifei.edu.br face centered cubic cage, while the metallic cations occupy interstices. The metallic cations outside the bracket occupy the tetrahedral sites ( $A$ sites) comprising tetrahedral sublattice while those metallic cations enclosed by the bracket occupy octahedrally sites ( $B$ sites) comprising the octahedrally sublattice. Figure 1 shows a representation of the unit cell of the $\mathrm{Mn}-\mathrm{Cu}$ ferrite. In tetrahedral $(A)$ site, the interstice is in the centre of a tetrahedron formed by four lattice atoms. Four anions are occupied at the four corners of a cube and the cation occupies the body centre of the cubicfcc. In octahedral sites $(B)$, interstice is at the centre of an octahedron formed by 6 regular anions. The oxygen atom is represented by spheres ${ }^{6}$.

The spinel formation reaction by solid-state reaction is so slow because all of the ions $\mathrm{Fe}^{2+}, \mathrm{Cu}^{+2}, \mathrm{Mn}^{+2}$ diffuse slowly. Defects are formed, particularly vacancies adjacent sites at which ions can emerge. High temperatures for extended periods are necessary so that the ions have sufficient thermal energy to occasionally vibrate or jump from one site into an adjacent vacancy or interstitial ${ }^{7}$.

Both the cation distribution in the octahedral and tetrahedral sites and the grain size are crucial factors that determine the magnetic and electrical responses. The manganese ferrite is partial inverse spinel, where about $80 \%$ of $\mathrm{Mn}^{2+}$ ion occupy the tetrahedral $A$ sites: However, there are $\mathrm{Mn}^{3+}$ ions at the octahedral $\mathrm{B}$ sites, and are connected by the presence of $\mathrm{Fe}^{2+}$ ions also present at these ionic sites. The addition of impurities induces changes in structure and texture of the crystal ${ }^{8,9}$. References ${ }^{9,10}$ revealed that the magnetic performance and microstructure depend considerably on chemical composition and sintering temperature of samples.

With respect of electrical properties, it is desirable that a ferrite have as high resistivity as possible. This is necessary in order to avoid Foucault or Eddy currents that heat the material and loses energy, e.g. in a transformer. Improvements 


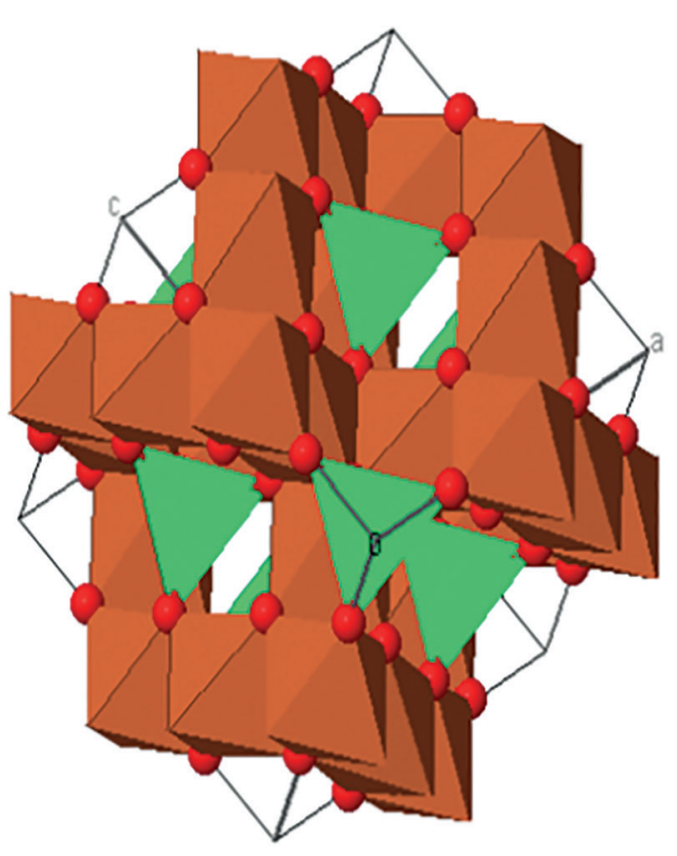

Figure 1: A fragment of the structure of $\mathrm{Mn}_{0.50} \mathrm{Cu}_{0.50} \mathrm{Fe}_{2} \mathrm{O}_{4}$.

in contrast to conventional metallic ferromagnetic materials that present very strong Eddy currents, which leads to high operating temperatures ${ }^{11}$ are possible with Ferrite materials since the crystallite boundaries act as energy barriers, confining charge carriers, i.e. electrons, into the grains.

In this work, we have carried out alternating current (a.c.) and continuous current (c.c.) electrical and magnetical characterization of mixed manganese/copper ferrite. X-ray diffraction (XRD), a vibrating sample magnetometer (VSM), were used in this study.

\section{Materials and Methods}

The high purity oxides of Manganese (MnO), cupper $(\mathrm{CuO})$ and iron $\left(\mathrm{Fe}_{2} \mathrm{O}_{3}\right)$ were mixed and compacted up to a uniaxial press of $39 \mathrm{GPa}$. After, samples with chemical formula $\mathrm{Mn}_{\mathrm{x}} \mathrm{Cu}_{1-\mathrm{x}} \mathrm{Fe}_{2} \mathrm{O}_{4}$ with manganese concentrations $\mathrm{x}$ of $0.40,0.42,0.44,0.46,0.48$ and 0.50 were synthesized at $1000^{\circ} \mathrm{C}$ during 45 hours and finally heated to $1200^{\circ} \mathrm{C}$ by $5 \mathrm{~h}$, in room atmosphere. The crystalline phases were identified by means X-ray diffraction experiments using a Panalytical $x$ 'pert diffractometer, $\mathrm{Cuk}_{\alpha}$ radiation, angular interval $2 \theta$ from $15^{\circ}$ to $80^{\circ}$, angular step of 0.02 and $1 \mathrm{~s}$ counting time.

The crystallite size was calculated for all the compositions using the high intensity peak and Scherer formula ${ }^{11}$ :

$$
\mathrm{L}=\frac{0,91 \lambda}{\beta \cos \theta}
$$

where $L$ is the crystalline size perpendicular to $(h k l)$ plane, $\lambda$ the wavelength of X-ray used ( $\lambda=1.5418 \AA$ ), $\beta$ full width at half maximum of the diffraction peak (FWHM) and $\theta$ the peak angular position. The lattice parameters, $a$, were measured by Rietveld ( FULLPROFF software). From EDX, the composition details of the prepared ferrites were determined.

The electronic conductivity was measured by Keithley 2400 source/measure unit and the temperature was varied in an oven with temperature control at a rate of $5 \mathrm{~K} / \mathrm{min}$ up to a temperature of $573 \mathrm{~K}$. The magnetic characterization was performed by means of a vibrating sample magnetometer Lakeshore model 7404. The magnetic parameters: coercive field $\mathrm{H}_{\mathrm{c}}$, saturation magnetization $\mathrm{M}_{\mathrm{s},}$ remanent magnetization $M_{R}$ were determined by the hysteresis curves with an applied field of $12 \mathrm{kG}$. The Curie temperature were determined by the thermo-magneto-gravimetric technique. The a.c. electrical measurements were carried using an impedance analyzer in the frequency range $1 \mathrm{~Hz}$ to $10 \mathrm{MHz}$.

The graph $\ln \left(\rho \mathrm{T}^{-1 / 2}\right)$ vs. 1000/T indicates a large linear region associated to the grain/barrier model. The linearity occurs in two distinct temperature ranges, the $E_{b}, N_{d}$ and $L_{D}$ values obtained from to the slope of both linear fittings according to the equation (2).

$$
E_{b}=\frac{(L / 2)^{2} e^{2} N_{d}}{8 \varepsilon \varepsilon_{0}}
$$

where $L$ is the average size of the crystallites determined from the Debye-Scherrer model (2), $E_{b}$ is the energy barrier height at the grain boundary, $\mathrm{N}_{\mathrm{d}}$ is the donor concentration, $\varepsilon$ is the relative dielectric constant at low frequency and $\varepsilon_{0}$ is the vacuum permittivity. $\varepsilon$ is determined as the asymptotic value calculated from a.c. impedance measurements at low frequency (determined in the range between $1 \mathrm{~Hz}$ and $10 \mathrm{Mhz}$ ) for all samples are shown in Table 2. This mechanism can be determined by Debye shielding length $\left(L_{D}\right)$ with equation (3). If $L_{D}<L / 2$, the potential barriers exist in the grain boundary region due to capture states at these interfaces ${ }^{12}$.

$$
L_{D}=\sqrt{\left(\frac{K_{B} T \varepsilon \varepsilon_{0}}{e^{2} N_{d}}\right)}
$$

\section{Results and Discussion}

Figure 2 shows the X-ray diffractograms of the samples. Was observed peaks to $\mathrm{Mn}_{\mathrm{x}} \mathrm{Cu}_{1-\mathrm{x}} \mathrm{Fe}_{2} \mathrm{O}_{4}(0.40<\mathrm{x}<0.50)$ ferrite correspond to standard spinel (JCPDS - file $\mathrm{n}^{\circ} 01$ 074-2072) diffraction patterns which confirmed the cubic structure with no extra peaks corresponding to other phases. The peaks indexed to (111), (220), (311), (222), (400), (422), (511) and (440) planes of a cubic unit cell, all planes are the allowed planes which indicates the formation of cubic spinel structure in single phase ${ }^{13}$.

The Figure 3 shows the lattice parameter values of the ferrites as function of Mn-concentration. This figure shows that the " $a$ " lattice parameter $a$ increases with increasing $\mathrm{Mn}$ content due to the difference in the ionic radii between $\mathrm{Mn}^{2+}(0.66 \AA)$ and $\mathrm{Cu}^{2+}(0.57 \AA)^{14}$. The increase in lattice parameter with composition can be explained on the basis of Vegard's law ${ }^{15}$. This law explains the linear variation in lattice parameter with the ionic radii of the doped and the 


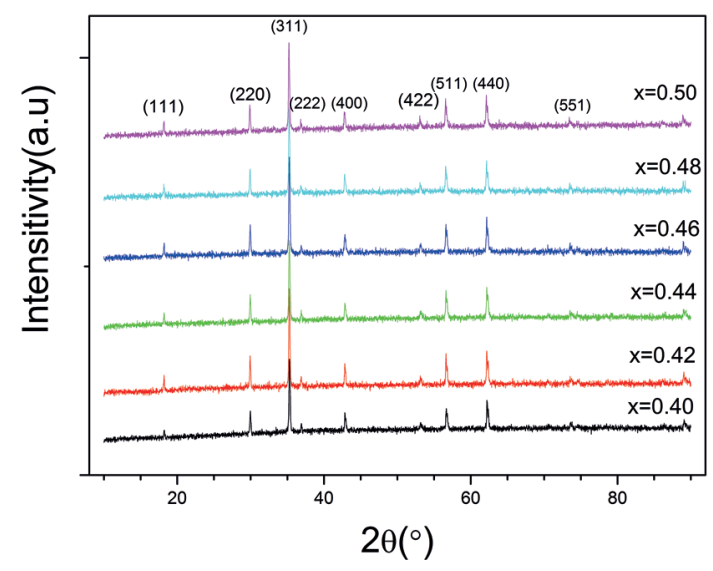

Figure 2: X-ray diffraction (XRD) patterns of the ferrites with different compositions.

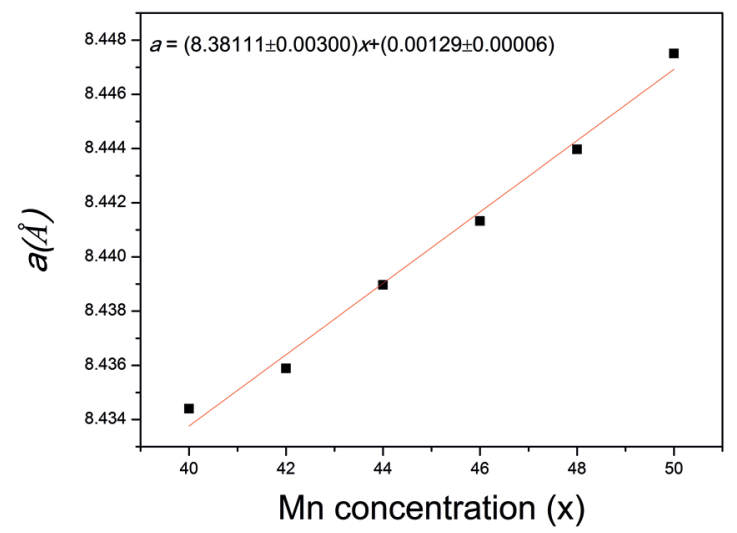

Figure 3: Lattice parameter as function of Mn-concentration for ferrites $(0.40<\mathrm{x}<0.50)$.

replacing ion. In the case we are replacing $\mathrm{Mn}^{2+}$ ion with $\mathrm{Cu}^{2+}$ ion. The lattice parameter is found to rise, which may be attributed to shifting on some $\mathrm{Fe}^{3+}$ ions form $A$ site to $B$ site for higher composition ${ }^{16}$. The lattice parameters found are between $a=8.41 \AA$ and $a=8.50 \AA$ for copper and manganese ferrites, respectively. The value of the lattice parameter obtained for the all samples is in good agreement with reported in literature ${ }^{14}$.

The EDX spectrum of $\mathrm{Mn}_{\mathrm{x}} \mathrm{Cu}_{1-\mathrm{x}} \mathrm{Fe}_{2} \mathrm{O}_{4}(0.40<\mathrm{x}<$ $0.50)$ gave the information on the elemental composition of the material. The elemental compositions agree with the stoichiometric relations of the prepared compound. Table 1 presents the semi-quantitative results of EDS disregarding the presence of the element oxygen, because this element is very light (atomic mass $15,9994 \mathrm{u} \pm 0,0004 \mathrm{u}$ ). It shows the ratio of $\mathrm{Mn} / \mathrm{Cu}$ experimental elements for each nominal composition of the samples.

The calculated values of crystallite size $(L)$ for the distinct compositions are shown in Table 1. The value of crystallite size was calculated from Scherrer Formula by the high intensity peak (311). The values of $L / 2$ range from $30 \mathrm{~nm}$ to $40 \mathrm{~nm}$. These values are valid for the application of conduction model limited by potential barriers located at crystallite boundaries.
Figure 4 show the temperature dependence of the electrical resistivity by the d.c measurements for all ferrites samples. In all samples, it was found that the resistivity of the material rise as a function of inverse temperature. The crystallite boundaries with potential barriers model is the electrical conduction mechanism observed for all samples at high temperatures. For them, the high value of resistivity is associated with the simultaneous presence of ferrous and ferric ions on equivalent lattice sites ${ }^{17}$.

In order to obtain parameters for Table 2, we considered one temperature in the center of both linear regions of Figure 4, i.e. $\mathrm{T}=473 \mathrm{~K}$.

As determined by the fitting parameters on Table 2 , the electrical conductivity of all samples of mixed manganese/ copper ferrite depends on boundaries. Since the barriers are high enough to avoid carriers to cross the crystallite boundaries and the low $L_{D}$ confirms this fact we can conclude that the electrical transport in polycrystalline ferrites is dominated by those boundary effects. With energy barriers of about $0.5 \mathrm{eV}$, the $\mathrm{Mn}_{\mathrm{x}} \mathrm{Cu}_{1-x} \mathrm{Fe}_{2} \mathrm{O}_{4}$ ferrite samples presents a semiconductor behavior but with activation energies with the resistivity having a preexponent factor $\mathrm{T}^{1 / 2}$, characteristic of conduction limited by potential barriers located at crystallite boundaries and confirmed by assuring $L_{D}<L / 2$ relation.

Figure 5 shows the hysteresis loops at room temperature of all samples. We can observe that saturation is attained at relatively low fields $(12 \mathrm{kG})$. It was possible to determine the values of some magnetic parameters such as the coercive field $(\mathrm{Hc})$, remanent magnetization $(\mathrm{Mr})$ and saturation magnetization (Ms). The results of measurement of the hysteresis of samples $\mathrm{Mn}_{x} \mathrm{Cu}_{1-x} \mathrm{Fe}_{2} \mathrm{O}_{4}$ obtained from the hysteresis curves in Figure 5 are shown in Table 2.The samples were measured at room temperature and the magnetization was normalized considering the total sample mass.

The $\mathrm{Mn}-\mathrm{Cu}$ ferrites have a supermagnetic behavior trend that is observed by the magnetization curve (Figure 5). The variation of saturation magnetization can be correlated to the distribution of cations due to the exchange interaction of tetrahedral $(A)$ and octahedral $(B)$ ions. The molecular magnetization $(M)$ is given by the difference between magnetization of $M B$ and $M A$ octahedral and tetrahedral sites, respectively, in which subnet $\mathrm{B}$ has a higher magnetization. Since $\mathrm{Cu}^{2+}$ ions have a magnetic moment less than $\mathrm{Mn}^{2+}$ ions, the replacement of $\mathrm{Cu}^{2+}$ ions by $\mathrm{Mn}^{2+}$ ions in octahedral sites should result in increased $\mathrm{M}_{\mathrm{s}}$.

The results of saturation magnetization as a function of manganese concentration are shown in Table 3 and can be identified also on Figure 5. There was an increase in the value of saturation magnetization with increasing manganese of $x=0.40$ to 0.46 and $x=0.40$ to 0.46 there is a decrease in saturation magnetization in the system $\mathrm{Mn}_{\mathrm{x}} \mathrm{Cu}_{1}$. ${ }_{x} \mathrm{Fe}_{2} \mathrm{O}_{4}$. This is attributed to decrease in magnetization of the sublattice $B$. This is achieved by two mechanisms, i.e. both the reduction of the magnetization of the sublattice $B$ due to the existence of $\mathrm{Cu}^{2+}$ with less time or more $\mathrm{Mn}^{2+}$ ions occupy the $\mathrm{A}$ sites, and more $\mathrm{Fe}^{3+}$ ions are forced to migrate to A sites. Thus, the result is a decrease in the 
Table 1: Percentage of atomic elements of ferrites $\mathrm{Mn}_{x} \mathrm{Cu}_{1-x} \mathrm{Fe}_{2} \mathrm{O}_{4}$.

\begin{tabular}{lcccc}
\hline Sample & $\begin{array}{c}\mathrm{Mn} \\
(\%)\end{array}$ & $\begin{array}{c}\mathrm{Cu} \\
(\%)\end{array}$ & $\begin{array}{c}\mathrm{Fe} \\
(\%)\end{array}$ & $\begin{array}{c}\mathrm{Mn} / \mathrm{Cu} \\
(\%)\end{array}$ \\
\hline MCF 40 & $12.45 \pm 0.32$ & $20.28 \pm 0.52$ & $65.3 \pm 1.4$ & $38.04 \pm 0.14$ \\
MCF42 & $14.34 \pm 0.34$ & $19.75 \pm 0.54$ & $65.9 \pm 1.4$ & $42.06 \pm 0.18$ \\
MCF44 & $14.74 \pm 0.36$ & $18.67 \pm 0.52$ & $66.6 \pm 1.5$ & $44.12 \pm 0.19$ \\
MCF46 & $13.83 \pm 0.37$ & $19.79 \pm 0.52$ & $66.4 \pm 1.4$ & $46.84 \pm 0.17$ \\
MCF48 & $15.37 \pm 0.33$ & $17.00 \pm 0.53$ & $67.4 \pm 1.5$ & $47.48 \pm 0.20$ \\
MCF50 & $16.20 \pm 0.29$ & $16.63 \pm 0.58$ & $67.2 \pm 1.4$ & $49.34 \pm 0.21$ \\
\hline
\end{tabular}

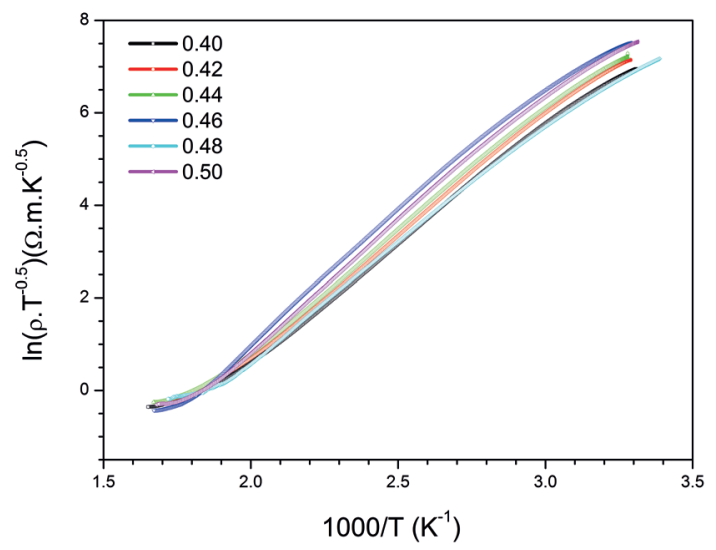

Figure 4: Temperature dependence of electrical resistivity plotted as $\ln (\rho \mathrm{T}-1 / 2)$ vs. $103 / \mathrm{T}$ of samples $\mathrm{Mn}_{\mathrm{x}} \mathrm{Cu}_{1-\mathrm{x}} \mathrm{Fe}_{2} \mathrm{O}_{4}$.

Table 2: Parameters of the grain/barrier model for all $\mathrm{Mn}_{x} \mathrm{Cu}_{1-x} \mathrm{Fe}_{2} \mathrm{O}_{4}$ samples. $\mathrm{x}$ is the composition factor, the $\varepsilon$ relative dielectric constant, the half of the average crystallite size $(L / 2)$, Debye shielding Length $\left(L_{D}\right)$. The last two columns are related to the ability of carriers to cross such barriers, i.e. $\mathrm{N}_{\mathrm{c}}$ the donor concentration and $\mathrm{E}_{\mathrm{b}}$ the energy barrier height).

\begin{tabular}{lccccc}
\hline $\mathrm{x}$ & $\varepsilon$ & $\mathrm{L} / 2(\mathrm{~nm})$ & $\mathrm{L}_{\mathrm{D}}(\mathrm{nm})$ & $\mathrm{N}_{\mathrm{c}}\left(10^{17} \mathrm{~cm}^{-3}\right)$ & $E_{b}(\mathrm{eV})$ \\
\hline 0.40 & 22.9 & 38.76 & 6.90 & 9.20 & 0.44 \\
0.42 & 37.5 & 34.76 & 6.76 & 15.7 & 0.45 \\
0.44 & 28.9 & 32.94 & 6.44 & 13.3 & 0.47 \\
0.46 & 21.2 & 32.09 & 6.57 & 9.39 & 0.49 \\
0.48 & 30.7 & 32.41 & 5.87 & 17.0 & 0.43 \\
0.50 & 18.6 & 37.13 & 7.97 & 5.59 & 0.49 \\
\hline
\end{tabular}

magnetic moment of the sublattice $B^{18}$. For samples with higher copper content, most $\mathrm{Cu}^{2+}$ occupies the octahedral sites and disturbs the ferromagnetic interactions between $\mathrm{Fe}^{3+}$ ions ${ }^{19}$.

With all these characterization techniques we infer that the ceramics exhibited characteristics of a soft magnetic material with high electric resistivity.

\section{Conclusion}

$\mathrm{Mn}_{\mathrm{x}} \mathrm{Cu}_{1-\mathrm{x}} \mathrm{Fe}_{2} \mathrm{O}_{4}$ ferrite $(0.40<\mathrm{x}<0.50)$ were synthesized by a conventional solid-state reaction method and investigated as potential materials for devices electronic and drug delivery.

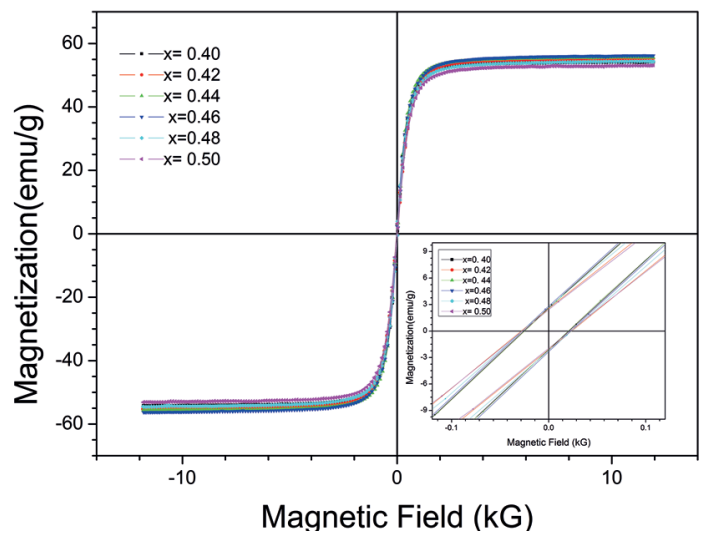

Figure 5: Hysteresis loops at room temperature of samples $\mathrm{Mn}_{\mathrm{x}} \mathrm{Cu}_{1}$. ${ }_{x} \mathrm{Fe}_{2} \mathrm{O}_{4}$. The inset corresponds to a zoom to help identifying the coercitive fields and remanent magnetization.

The system $\mathrm{Mn}_{\mathrm{x}} \mathrm{Cu}_{1-\mathrm{x}} \mathrm{Fe}_{2} \mathrm{O}_{4}$ is single phase spinel ferrite with cubic unit cell for all compositions. The X-ray analysis confirmed the formation of the single phase samples for the compositions $0.40<\mathrm{x}<0.50$ and shown that the lattice parameter " $a$ " increase linearly with increase Mn content, due to the ion substitution. A typical magnetization versus magnetic field $(\mathrm{M}-\mathrm{H})$ curve of $\mathrm{Mn}_{\mathrm{x}} \mathrm{Cu}_{1 \mathrm{x}} \mathrm{Fe}_{2} \mathrm{O}_{4}$ ferrite collected on a VSM shows an increase in magnetization as the magnetic field increases. The magnetization versus magnetic field curves collected are characteristic of soft magnetic materials. These mixed spinel ferrites are useful as magnetic devices due to low coercivity field $\mathrm{H}_{\mathrm{C}}$ and high saturation magnetization. In the study of manganese/copper ferrite, the resistivity is found to be decreased with increasing temperature for all samples. The ferrites show semiconducting behavior with conduction in crystallites with potential barriers located at crystallite boundaries as defined by x-ray data and calculations of Debye length. We have shown that electron transport in the investigated samples is dominated by grain/barrier model adapted to this crystallite scenario at high temperatures $(\mathrm{T}=423 \mathrm{~K})$.

\section{Acknowledgments}

The authors are grateful to the Brazilian agencies, National Counsel of Technological and Scientific Development (CNPq), Coordination for the Improvement of Higher Level -or Education- Personnel (CAPES) and Foundation for Research Support of the State of Minas Gerais (FAPEMIG). 
Table 3: Results for the hysteresis measurements of samples $\mathrm{Mn}_{\mathrm{x}} \mathrm{Cu}_{1-\mathrm{x}} \mathrm{Fe}_{2} \mathrm{O}_{4}$

\begin{tabular}{lccccc}
\hline $\mathrm{x}$ & $\mathrm{M}_{\mathrm{s}}(\mathrm{emu} / \mathrm{g})$ & $\mathrm{M}_{\mathrm{r}}(\mathrm{emu} / \mathrm{g})$ & $\mathrm{H}_{\mathrm{c}}(\mathrm{G})$ & $\mathrm{M}_{\mathrm{s}} / \mathrm{M}_{\mathrm{r}}$ & $\mathrm{Tc}(\mathrm{K})$ \\
\hline 0.40 & $53.94 \pm 0.05$ & $3.847 \pm 0.004$ & $23.132 \pm 0.002$ & 14.02 & 636 \\
0.42 & $55.20 \pm 0.06$ & $3.989 \pm 0.004$ & $26.114 \pm 0.003$ & 13.84 & 633 \\
0.44 & $55.63 \pm 0.06$ & $2.500 \pm 0.002$ & $16.468 \pm 0.002$ & 22.25 & 632 \\
0.46 & $56.06 \pm 0.06$ & $6.349 \pm 0.006$ & $16.337 \pm 0.002$ & 8.83 & 631 \\
0.48 & $54.16 \pm 0.05$ & $3.849 \pm 0.004$ & $25.902 \pm 0.003$ & 14.07 & 624 \\
0.50 & $53.08 \pm 0.05$ & $2.844 \pm 0.003$ & $22.98 \pm 0.002$ & 18.66 & 632 \\
\hline
\end{tabular}

\section{References}

1. Chen D, Liu HY, Li L. One-step synthesis of manganese ferrite nanoparticles by ultrasonic wave-assisted ball milling technology. Materials Chemistry and Physics. 2012;134(2-3):921-924.

2. Kumar ER, Jayaprakash R, Devi GS, Reddy PSP. Synthesis of $\mathrm{Mn}$ substituted $\mathrm{CuFe}_{2} \mathrm{O}_{4}$ nanoparticles for liquefied petroleum gas sensor applications. Sensors and Actuators B: Chemical. 2014;191:186-191.

3. Kumar ER, Jayaprakash R, Devi GS, Reddy PSP. Magnetic, dielectric and sensing properties of manganese substituted copper ferrite nanoparticles. Journal of Magnetism and Magnetic Materials. 2014;355:87-92.

4. Rosales MI, Plata AM, Nicho ME, Brito A, Ponce MA, Castaño VM. Effect of sintering conditions on microstructure and magnetic properties of $\mathrm{Mn}-\mathrm{Zn}$ ferrites. Journal of Materials Science. 1995;30(17):4446-4450.

5. Sharma US, Sharma RN, Shah R. Physical and Magnetic Properties of Manganese Ferrite Nanoparticles. International Journal of Engineering Research and Applications. 2014;4(8):14-17.

6. Goldman A. Modern Ferrite Technology. New York: Springer; 2006.

7. Zhang S, Lee W. Spinel-Containing Refractories. In: Schacht CA, ed. Refractories Handbook. New York: Marcel Dekker; 2004. p.215-258.

8. Deraz NM, Alarifi A. Microstructure and Magnetic Studies of Zinc Ferrite Nano-Particles. International Journal Electrochemical Science. 2012;7:6501-6511.

9. Xiao Z, Shaohua J, Wang X, Li W, Wang J, Liang C. Preparation, structure and catalytic properties of magnetically separable $\mathrm{Cu}-$ Fe catalysts for glycerol hydrogenolysis. Journal of Materials Chemistry. 2012;32:16598-16605.
10. Moulson AJ, Herbert JM. Electroceramics: Materials-PropertiesApplications. $2^{\text {nd }}$ ed. New Jersey: John Wiley \& Sons Ltd; 2003. 576p.

11. Cullity BD. Elements of X-Ray Diffraction. Reading: Addison Wesley; 1956.

12. Mardare D, Iftimie N, Crișan M, Răileanu M, Yildiz A, Coman $\mathrm{T}$, et al. Electrical conduction mechanism and gas sensing properties of Pd-doped $\mathrm{TiO}_{2}$ films. Journal of Non-Crystalline Solids. 2011;357(7):1774-1779.

13. Mazen SA, Mansour SF, Zaki HM. Some physical and magnetic properties of Mg-Zn ferrite. Crystal Research \&Technology. 2003;38(6):471-478.

14. Shannon RD. Revised effective ionic radii and systematic studies of interatomic distances in halides and chalcogenides. Acta Crystallographica Section A. 1976;32(5):751-767.

15. Rana MU, Misbah-ul-Islam, Abbas T. Cation distribution in $\mathrm{Cu}$-substituted manganese ferrites. Materials Letters. 1999;41(2):52-56.

16. Whinfrey CG, Eckart DW, Tauber A. Preparation and X-Ray Diffraction Data for Some Rare Earth Stannates. Journal of the American Chemical Society. 1960;82(11):2695-2697.

17. Smit J, Wijn HPJ. Ferrites. Eindhoven: Philips Technical Library; 1959. p.229-242.

18. Azab A, EL-Khawas EH. Synthesis and Magnetic anomalies of Copper Manganese ferrite $\mathrm{Mn}_{1-\mathrm{x}} \mathrm{CuxFe}_{2} \mathrm{O}_{4}(0.0 \leq \mathrm{x} \leq 0.7)$. Journal of Applied Sciences Research. 2013;9(3):1683-1689.

19. Cao JG, Li JJ, Duan HF, Lin YJ. Synthesis and Characterization of Manganese-copper Spinel Ferrite Powders. Chemical Research in Chinese Universities. 2012;28(4):590-593. 